\title{
INTERNATIONAL \\ Effects of the physicochemical properties of pellets on the germination of pelleted sugar beet seeds
}

\author{
Stawomir Z. Podlaski (, Hanna Wzorek, and Chrystian M. Chomontowski* \\ Department of Plant Physiology, Faculty of Agriculture and Biology, Warsaw University of Life Sciences SGGW, \\ Nowoursynowska 159, 02-776 Warsaw, Poland
}

Received April 5, 2018; accepted November 13, 2018

\begin{abstract}
The effects of the physicochemical characteristics of pellets, when applied to sugar beet seeds originating from ten seed companies, on the germination of pelleted seeds were assessed. The most significant factor was the force necessary to break the pellet, which was found to positively correlate with pellet's abrasion resistance, and negatively with pellet's water resistance. Pellets dissolved in water, characterized by low water resistance, negatively affected germination under the conditions of excess water in the filter paper. A low water potential of pellets inhibited seed germination, particularly with the shortfall of water in the germination medium. The water flow between the pellet and the pericarp was of much importance for germination. Under the conditions of the shortfall and excess of water in the germination medium, the physicochemical properties pellets had a greater effect on the drawing of water, and on the water flow between the pellet and the seeds, than under the optimum moisture conditions. Organic pellets were characterized by a greater ability to absorb water than mineral or organic-mineral pellets. The pellets varied in their chemical composition, with the greatest variation (over ninety-fold) relating to pellet's copper content. The following values exhibited low variety: $\mathrm{Zn}, \mathrm{Mn}$, and $\mathrm{Pb}$. It can be concluded that pellet's cracking force and water resistance are the basic parameters of pellet quality, and the swelling ability of pellets is determined by their organic or monaural composition.

Keywords: swelling ability, total porosity, water potential, water content
\end{abstract}

\section{INTRODUCTION}

Seed pelleting involves covering a fruit with a layer of a substance that causes an increase in the mass and size of the seed, as well as a change in the shape to one that is close to spherical (Copeland and McDonald, 2001; Halmer, 2000; Taylor et al., 1998). Germination of pelleted sugar

*Corresponding author e-mail: chrystian_chomontowski@sggw.pl beet seeds depends on the biological properties (vigour) of botanical seeds, as well as on the physical and physicochemical properties of the pericarp and the pellet. In the study by Litwiniak (2006), the mean time for a single seed to germinate (Pieper's coefficient) increased by 3.1 days after pelleting, in comparison to non-pelleted seeds. In the case of a washed seed, the increase was 2.5 days, while for washed and primed seed it was 1.5 days. The presented data indicate that there is a strong interaction between seed characteristics and pelleting effects.

When the radicle appeared, in most cases the water potential of botanical seeds oscillated around -1 MPa (Bradford, 1994; Podlaski, 1997). Consequently, every factor that limits or delays the gaining of such potential by the botanical seeds extends their germination duration. A low water potential also hampers the water flow between the pellet, the pericarp and the seed. The water diffusion coefficient of the pellet and the pericarp constitutes a way to measure the flow rate. Podlaski (2000) demonstrated that the pericarp's water diffusion coefficient, determined after $24 \mathrm{~h}$ of contact with wet filter paper, was $3.410^{-4} \mathrm{~cm}^{2}$ $\mathrm{d}^{-1}$. A high content of inorganic mineral compounds, which form water-soluble crystals, in the pericarp, as well as a high pericarp thickness and low porosity result in lowering the pericarp's water diffusion coefficient value (Podlaski, 2000).

According to Taylor and Salanenka (2012), the diffusion ability of a particular chemical compound through the seed coat depends on the interaction between the chemical structure of the seed-covering tissues and the physicochemical properties of the compound applied. 
One measure of the water binding force in the pellet is its water potential. In the study by Podlaski (1997), after $24 \mathrm{~h}$ of contact with wet filter paper, moistened with a certain amount of water optimal for germination $(60 \%$, full water capacity - FWC), the water potential of pellets manufactured by various companies ranged from -2.3 to $-1 \mathrm{MPa}$. Pellet's water potential was positively correlated with the seed's germination capability and rate, both 4 and 14 days after the commencement of the germination test.

The pellet is composed of certain pelleting material and an adhesive. Pellets may also have other compounds added, such as pesticides, inoculants (micro-organisms), micronutrients, calcium, manganese oxide, peroxides (Halmer, 2000; Hoseini et al., 2013) and nanomaterials (Podlaski et al., 2016; Sekhon 2014). The properties and dosage of the pelleting material and the adhesive must be compatible with the seeds so that seed quality is maintained and the germination itself is not hindered (Halmer, 2000).

The physical and chemical properties of the pelleting material and the adhesive provide a variety of mechanical and biological outcomes for coating. Particle size distribution affects pellet quality, whereby small particles provide higher physical resistance but limited gas and water exchange whereas larger particles increase porosity but reduce mechanical integrity and coat resilience (Pedrini et al., 2017).

The pelleting of seeds involves both science and art. The selection of both the powders and adhesives is mainly based on science, while knowing when and how much adhesive and coating material should be added is an art that takes time and practice to perfect (Harris Moran, 2012).

Halmer (2000) also stressed that "the development of coatings, as with pesticide formulation, is largely an empirical matter, and a great deal depends upon skill and art as well as trial and error. The pelleting process is carried out at specialist facilities, which are usually run on a confidential basis. Most of technology is, therefore, proprietary".

An understanding of how different pellet characteristics affect the quality of pelleted seeds is becoming even more important as many companies are starting to use fully automated seed treatment lines. Under such conditions, the quality of the pellet depends, to a greater extend, on science than on art.

The research focus of the academic circles and the seed industry, in field of seed pelleting, has diverged, with private companies improving the mechanical properties of pellets, and the scientific community concentrating on evaluating the efficiency and impact of active ingredients on germination, plant establishment and performance (Pedrini et al., 2017).

Regardless of the method used for seed production, a knowledge of the effects of various pellet characteristics on the properties of pelleted seeds and seed germination is always necessary. Expanding this knowledge is the purpose of this paper.
The aim of the study was to:

1. develop the appropriate methods of assessing pellet characteristics in terms of seeds germination;

2. assess these pellet properties, including determination of their range of variability;

3 . assess the effects of selected pellet characteristics on pelleted seeds germination.

\section{MATERIALS AND METHODS}

Our tests covered both pelleted and coated seeds of different beet varieties, manufactured by ten European seed companies, i.e. Betaseed, Florimond Desprez, Kalinowa, Kutnowska, Wielkopolska Sugar Beeet Breeding Companies, KWS AG, Novartis, SES-Europe, Strube-Dieckmann and Vanderhave. Their quality was assessed at the Warsaw University of Life Sciences (WULS), the Department of Plant Physiology, as part of experiments conducted by the Research Centre for Cultivar Testing (COBORU). The study was conducted between 2005 and 2009, and each year 1-3 varieties obtained from each company were analysed (64 varieties in total). The companies were marked with letters from A to J. Some of the seeds were pelleted using the same technology, e.g. the seeds belonging to companies $\mathrm{A}, \mathrm{F}$, and $\mathrm{G}$.

The pelleting of sugar beet seeds was assessed by determining various physicochemical and physical characteristics (of the entire pellet) that could potentially affect seed germination, under varied water moisture levels of the filter paper $(40,60,80 \% \mathrm{FWC})$, used as the germination medium. The effects of the pellet on seed germination were assessed by comparing the quality of pelleted seeds with the same seeds having their pellets removed mechanically.

Several new methods were developed after a series of preliminary tests. They included measuring and assessing pellet's cracking force, abrasion resistance, water resistance, swelling, total porosity, total water potential and the pelleted seed matrix potential. On the basis of the obtained results, simple mechanical devices for the evaluation of the cracking force and abrasion resistance of pellets were created. In relation to other methods, many years of own experience in the field of research on sugar beet seeds were used, along with basic physical methods to determine some features, such as volume or density.

The force necessary to crack the pellet was measured using a special device, as shown in Fig. 1. The main part of the device was an anvil where pelleted seeds were placed one at a time. The seeds were then pressed to the anvil by a hammer connected to a long lever, on which weights were moved. The product of the arm length and weight mass delivered the value of force by statically acting on a single pelleted seeds.

A total of $3 \times 50$ seeds from each variety were used for test purposes. The following forces were applied to each pelleted seed in succession: 4.905, 9.810, 14.715, 19.620, 


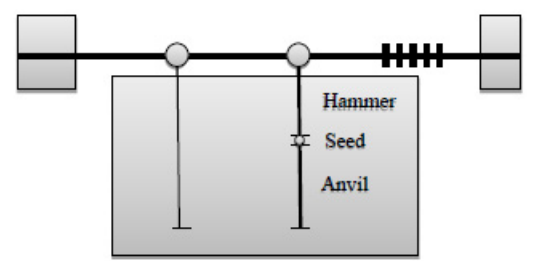

Fig. 1. A scheme of the device for pellet measurement.

24.525 and $29.430 \mathrm{~N}$. Each time, the number of seeds whose pellets cracked under the specific force was counted. The mean value of the force necessary to crack all the pellets was calculated as the sum of the products of seeds and the force necessary to crack the pellet of each seed, divided by the total number of seeds.

The pellet's abrasion resistance test was conducted using a simple scarification drum. Five hundred pelleted seeds provided by each company, in three replicates, were poured into a container (a scarification drum with a diameter of $-15 \mathrm{~cm}$ and a depth of $-8 \mathrm{~cm}$ ), where two planes rotated at a speed of 500 r.p.m., around a common axis for $30 \mathrm{~s}$ in total. Afterwards, the seeds were divided into three groups, i.e. seeds with undamaged pellets, seeds with partly damaged (partially abraded) pellets, and seeds completely devoid of pellets. The results presented in this paper concern the percentage of seeds with undamaged pellets.

A total of $4 \times 5000$ seeds provided by each company were used for test purposes, and poured into a cylinder containing 0.51 of water. One day later, the fruits were poured onto a sieve, and the numbers of pellets that had dissolved completely, abraded partially or remained undamaged were determined. The report only contains data on the percentage of undamaged seeds.

Two hundred seeds with mechanically removed pellets, in three replicates, and the pelleted seeds of each sample were placed between two layers of filter paper moistened with water up to $60 \% \mathrm{FWC}$. The paper was covered with a polyethylene film to prevent it from drying. After $24 \mathrm{~h}$, the wet pelleted and depelleted seeds were removed from the filter paper and gently screened on sieves with $2.5 ; 3.0$; $3.5 ; 4.0 ; 4.5$ and $5.0 \mathrm{~mm}$ holes.

Based on the number of fruits on each sieve, the mean weighted diameter was estimated for a single depelleted and single pelleted seed. The difference between the mean weighted diameter of one wet depelleted and pelleted seed was calculated, and so was the swelling ability of pellets. The results were expressed in $\mathrm{mm}$.

In a narrow burette filled with toluene, 50 pelleted seeds and seeds with mechanically removed pellets were immersed in 4 replicates. Based on the difference in volumes, the volume of the pellets in the sample was obtained. When determining pellet's moisture content $24 \mathrm{~h}$ after being placed on the wet filter paper at $60 \% \mathrm{FWC}$, the volume of water $\left(1 \mathrm{~g}\right.$ of water $\left.=1 \mathrm{~cm}^{3}\right)$ contained in the pellet was determined as well. Usually, after $24 \mathrm{~h}$, an equilibrium was achieved between the moisture content of the filter paper and the pellet. The ratio of the volume of water contained in the pellet to the entire pellet volume was used to determine total porosity.

The total pellet water potential was assessed 24, 48 and $72 \mathrm{~h}$ after placing the pelleted seeds on the filter paper with a moisture content of $60 \%$ FWC, using a Wescor Inc. (Utah, USA) voltmeter and a C-52 sample chamber.

The WC of the pellets was determined after drying at $105^{\circ} \mathrm{C}$ for $3 \mathrm{~h}$, and expressed on a fresh mass basis. The WC was measured using 3 replicates of 50 pellets each. The WC of depelleted seeds was estimated after drying at $105^{\circ} \mathrm{C}$ for $5 \mathrm{~h}$. Seed sieves with rectangular openings were used to remove the pellet. The width of the holes was equal to the diameter of unpelleted seeds, about $3.5 \mathrm{~mm}$. The diameter of pelleted seeds was $4.5-5.0 \mathrm{~mm}$. The rubber roller gently pressed the pelleted seeds to the sieves, which caused the pellet to crack and be partially removed. Pellet cracking was stimulated by differences in the width of the sieves and the diameter of the pericarp. The side walls of the sieves affected the pellet, causing it to crack. Residues of the pellet were removed with a brush. In addition, the seeds were dusted in the air stream.

As regards all the samples, pellets were mechanically removed from seeds. The ground pellets were analysed on an atomic spectrophotometer in the WULS Physicochemical Laboratory. Knowing the mean pellet weight, the content of individual elements could be determined in respect of a single pellet.

Respiration was measured using the photometric method involving the determination of $\mathrm{CO}_{2}$ generation using a Li-cor (Nebraska, USA) in 3 replicates. A LI 6200 gas analyser operated in a closed system, and the presented results were expressed in $\mathrm{mg} \mathrm{CO}_{2} \mathrm{~h}^{-1} \mathrm{~g}^{-1}$ of fresh seeds mass.

The pelleted and depelleted seeds were germinated under both the optimum moisture and water excess conditions. The seeds belonged to two varieties manufactured by companies $\mathrm{G}$ and $\mathrm{C}$, which differed mainly in terms of the water resistance of pellets.

The seeds were germinated in standard containers on corrugated filter paper, 100 seeds in 3 replicates, at $20^{\circ} \mathrm{C}$. Germination was conducted under the optimum moisture conditions at $60 \% \mathrm{FWC}$, and under the water shortfall and excess conditions in the germination medium at $40 \%$ and $80 \%$ FWC, respectively. The seeds were counted daily. The germination process started once the visible germinal root had appeared. After 24, 48 and $72 \mathrm{~h}$ of germination, the pellets were removed from the seeds to determine the moisture content of both the pellets and the seeds.

Germination speed (GS) was estimated as the mean time to germinate (MTG), according to the following formula: $M T G=\sum\left(n_{i} \times d_{i}\right) / N$, where $n_{i}$ is the number of germinated seeds on day $i, d_{i}$ is the incubation period in days, and $N$ is the total number of germinated seeds. 
All data were subjected to the analysis of variance (ANOVA) and Tukey's test $(\mathrm{p}<0.05)$ to compare the mean values, (Statgraphics Ver.4. w 3.1 was used. Stars*, ** indicate the value of correlation coefficients $(r)$ at five and one percent of significance, respectively. Different small letters in the table denote the difference at $\mathrm{p}<0.05$.

\section{RESULTS}

The mean values of the pellet characteristics for 10 seed companies are presented in Table 1. Special attention should be paid to the pellets manufactured by companies $\mathrm{C}, \mathrm{F}$ and $\mathrm{G}$. Company $\mathrm{C}$ manufactured pellets that required a moderate force to crack, with high abrasion resistance and the highest water resistance, as well as the lowest swelling ability which corresponded to half the mean value for 10 companies.

Pellets manufactured by companies $\mathrm{F}$ and $\mathrm{G}$ were characterized by low cracking and abrasion resistance, markedly lower water resistance, average swelling and high porosity, as well as varied water potential after $24 \mathrm{~h}$ of pellet's contact with filter paper.

Table 1. Profiles of selected pellet characteristics

\begin{tabular}{ccccccc}
\hline Companies & $\begin{array}{c}\text { Cracking } \\
\text { force } \\
(\mathrm{N})\end{array}$ & $\begin{array}{c}\text { Abrasion resistance } \\
(\%)\end{array}$ & $\begin{array}{c}\text { Water } \\
\text { resistance } \\
(\%)\end{array}$ & $\begin{array}{c}\text { Swelling } \\
\text { ability of } \\
\text { pellets }(\mathrm{mm})\end{array}$ & $\begin{array}{c}\text { Total porosity } \\
(\%)\end{array}$ & $\begin{array}{c}\text { Water potential } \\
(\mathrm{MPa})\end{array}$ \\
\hline $\mathrm{A}$ & $24.3 \mathrm{c}$ & $94.1 \mathrm{~b}$ & $35.1 \mathrm{a}$ & $0.37 \mathrm{~b}$ & $58.2 \mathrm{bc}$ & $-1.3 \mathrm{c}$ \\
$\mathrm{B}$ & $21.6 \mathrm{~b}$ & $95.2 \mathrm{~b}$ & $46.4 \mathrm{~b}$ & $0.65 \mathrm{~d}$ & $79.6 \mathrm{e}$ & $-1.3 \mathrm{c}$ \\
$\mathrm{C}$ & $23.5 \mathrm{bc}$ & $97.1 \mathrm{~b}$ & $97.6 \mathrm{c}$ & $0.22 \mathrm{a}$ & $56.0 \mathrm{bc}$ & $-1.1 \mathrm{~cd}$ \\
$\mathrm{D}$ & $27.7 \mathrm{~d}$ & $97.5 \mathrm{c}$ & $90.7 \mathrm{c}$ & $0.45 \mathrm{c}$ & $42.3 \mathrm{a}$ & $-1.2 \mathrm{~cd}$ \\
$\mathrm{E}$ & $27.4 \mathrm{e}$ & $98.5 \mathrm{~cd}$ & $89.2 \mathrm{c}$ & $0.49 \mathrm{c}$ & $61.0 \mathrm{bcd}$ & $-1.1 \mathrm{~cd}$ \\
F & $21.6 \mathrm{~b}$ & $90.1 \mathrm{a}$ & $26.1 \mathrm{a}$ & $0.40 \mathrm{~b}$ & $66.7 \mathrm{~d}$ & $-1.0 \mathrm{~d}$ \\
$\mathrm{G}$ & $18.9 \mathrm{a}$ & $87.6 \mathrm{a}$ & $35.2 \mathrm{ab}$ & $0.44 \mathrm{c}$ & $68.0 \mathrm{~d}$ & $-1.8 \mathrm{a}$ \\
H & $25.7 \mathrm{c}$ & $95.2 \mathrm{bc}$ & $90.2 \mathrm{c}$ & $0.45 \mathrm{c}$ & $41.9 \mathrm{a}$ & $-1.3 \mathrm{c}$ \\
$\mathrm{I}$ & $25.5 \mathrm{c}$ & $94.1 \mathrm{~b}$ & $89.0 \mathrm{c}$ & $0.38 \mathrm{~b}$ & $54.0 \mathrm{~b}$ & $-1.6 \mathrm{ab}$ \\
J & $22.8 \mathrm{~b}$ & $95.1 \mathrm{bc}$ & $87.6 \mathrm{c}$ & $0.39 \mathrm{~b}$ & $45.1 \mathrm{a}$ & $-1.5 \mathrm{bc}$ \\
Means & 23.9 & 94.4 & 68.7 & 0.42 & 57.3 & -1.3 \\
\hline
\end{tabular}

$\mathrm{a}, \mathrm{b}, \mathrm{c}, \mathrm{d}-$ different small letters in the table denote the difference at $\mathrm{p}<0.05$.

Table 2. Correlation matrix between some selected properties of pellets

\begin{tabular}{lccccccc}
\hline Properties & $\begin{array}{c}\text { Cracking } \\
\text { force }\end{array}$ & $\begin{array}{c}\text { Abrasion } \\
\text { resistance }\end{array}$ & $\begin{array}{c}\text { Water } \\
\text { resistance }\end{array}$ & $\begin{array}{c}\text { Sweling } \\
\text { ability }\end{array}$ & $\begin{array}{c}\text { Total } \\
\text { porosity }\end{array}$ & $\begin{array}{c}\text { Water } \\
\text { potential }\end{array}$ & $\begin{array}{c}\text { Moisture } \\
\text { content }\end{array}$ \\
\hline Cracking force & - & $0.722^{*}$ & $0.678^{*}$ & -0.241 & $-0.760^{*}$ & 0.279 & -0.256 \\
Abrasion resistance & $0.722^{*}$ & - & $0.757^{*}$ & 0.004 & -0.410 & 0.500 & -0.563 \\
Water resistance & $0.678^{*}$ & $0.757^{*}$ & - & -0.272 & $-0.695^{*}$ & 0.095 & -0.522 \\
Sweling ability & -0.241 & 0.004 & -0.272 & - & 0.431 & 0.087 & $0.787^{* *}$ \\
Total porosity & $-0.760^{*}$ & -0.410 & $-0.695^{*}$ & 0.431 & - & 0.025 & $0.683^{*}$ \\
Water potential & 0.279 & 0.500 & 0.095 & 0.087 & 0.002 & - & -0.064 \\
Moisture content & -0.256 & -0563 & -0.522 & $0.787 * *$ & $0.683 *$ & 0.064 \\
\hline
\end{tabular}

$*,{ }^{* *}$ Significant at $\mathrm{p} \leq 0.05$ and $\mathrm{p} \leq 0.01$, respectively.
The data presented in Table 1 clearly indicate the existence of connections between certain pellet characteristics. The pair correlation coefficients between physical and physicochemical characteristics are presented in Table 2.

The strongest connection was found to exist between the mean pellet cracking force, which correlated positively with abrasion resistance and water resistance, and negatively with total porosity. The regression equation analysis indicated that if the pellet cracking force increased by $1 \mathrm{~N}$, its porosity decreased by 3.6\% (Fig. 4a).

Water resistance was positively correlated with pellet's cracking force and rubbing resistance, and inversely with porosity. The regression equation between porosity (y) and This means that if pellet's water resistance increased by $10 \%$ within the 35.1 to $97.6 \%$ range, its porosity decreased by $2.9 \%$.

A weak connection of $r=0.431$ (Table 2) was noted between swelling and porosity. This probably resulted from the varied composition of pellets manufactured by different companies. water resistance $(x)$ took the form of $y=-0.2929 x+77.4$. 
Table 3. Water content (\%) in pellets and seeds after $24 \mathrm{~h}$ since germination test start and differences in water content between pellets and seeds during germination

\begin{tabular}{ccccccc}
\hline \multirow{2}{*}{ Companies } & \multicolumn{2}{c}{$\begin{array}{c}\text { Water content (\%) } \\
24 \mathrm{~h} \text { after germination test start }\end{array}$} & & \multicolumn{3}{c}{$\begin{array}{c}\text { Difference in water content (\%) between pellets and seeds } \\
\text { after a specific germination time (h) }\end{array}$} \\
\cline { 2 - 3 } \cline { 5 - 6 } \cline { 5 - 6 } & seeds & pellets & & 24 & 48 & 72 \\
\hline $\mathrm{A}$ & $23.3 \mathrm{bc}$ & $36.0 \mathrm{~d}$ & & $12.7 \mathrm{ef}$ & $12.3 \mathrm{~d}$ & $11.4 \mathrm{~d}$ \\
$\mathrm{~B}$ & $19.4 \mathrm{a}$ & $40.5 \mathrm{e}$ & & 21.1 & $20.1 \mathrm{e}$ & $16.3 \mathrm{e}$ \\
$\mathrm{C}$ & $21.5 \mathrm{~b}$ & $23.0 \mathrm{a}$ & & $1.5 \mathrm{a}$ & $3.1 \mathrm{a}$ & $3.6 \mathrm{a}$ \\
$\mathrm{D}$ & $23.2 \mathrm{bc}$ & $33.6 \mathrm{c}$ & & $10.4 \mathrm{~d}$ & $8.9 \mathrm{c}$ & $7.5 \mathrm{~b}$ \\
$\mathrm{E}$ & $25.2 \mathrm{c}$ & $32.5 \mathrm{bc}$ & & $7.3 \mathrm{~b}$ & $6.2 \mathrm{~b}$ & $6.7 \mathrm{~b}$ \\
$\mathrm{~F}$ & $25.3 \mathrm{c}$ & $34.7 \mathrm{c}$ & & $9.4 \mathrm{c}$ & $8.3 \mathrm{c}$ & $6.4 \mathrm{~b}$ \\
$\mathrm{G}$ & $18.4 \mathrm{a}$ & $29.5 \mathrm{~b}$ & & $11.1 \mathrm{de}$ & $12.6 \mathrm{~d}$ & $11.4 \mathrm{~d}$ \\
$\mathrm{H}$ & $23.1 \mathrm{bc}$ & $31.9 \mathrm{~b}$ & & $8.8 \mathrm{c}$ & $8.0 \mathrm{c}$ & $4.6 \mathrm{a}$ \\
$\mathrm{I}$ & $18.4 \mathrm{a}$ & $30.5 \mathrm{~b}$ & & $12.1 \mathrm{e}$ & $12.3 \mathrm{~d}$ & $9.5 \mathrm{c}$ \\
$\mathrm{J}$ & $22.9 \mathrm{bc}$ & $35.8 \mathrm{~d}$ & & $12.9 \mathrm{ef}$ & $12.5 \mathrm{~d}$ & $9.3 \mathrm{c}$ \\
Means & 22.1 & 32.8 & & 10.7 & 10.4 & 8.7 \\
\hline
\end{tabular}

Explanations as in Table 1.
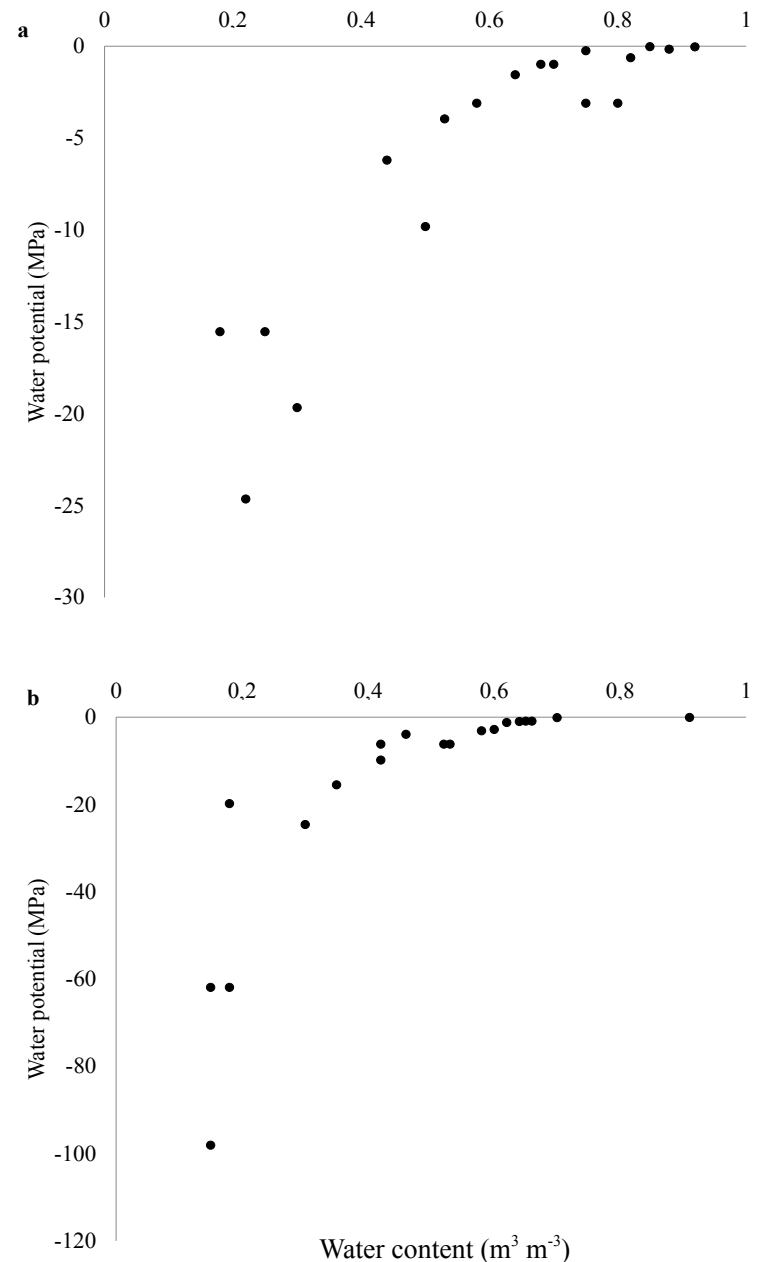

Fig. 2. The relationship between the gravimetric water content and matrix potential of the pellets produced by two seed companies: $\mathrm{a}$ - company $\mathrm{C}$, and $\mathrm{b}$ - company $\mathrm{G}$.
Pellet's water potential assessed after $24 \mathrm{~h}$ of pellet's contact with wet filter paper was weakly connected with other physical and physicochemical characteristics of the pellet (Table 2).

A major positive relation between pellet's swelling ability and the water content in the pellet (Table 2) was noted, while no such relation was observed between pellet's swelling ability and the water content in the seeds. This indicates that, at least in the case of pellets manufactured by some companies, the water flow between the pellet and the pericarp was reduced, and a higher water content in the pellet was not always related to a higher water content in the seeds, (company B), and vice versa (companies $\mathrm{E}, \mathrm{F}$ ) (Table 3).

The dynamics of the pellet water potential change varied, depending on the manufacturer. Figure 2 presents a comparison of the water potential change dynamics of two extremely different pellets manufactured by companies $\mathrm{C}$ and $\mathrm{G}$.

The pellets provided by company $\mathrm{C}$ are characterized by a significantly slower increase in the water matrix potential, increasing the water content, as compared to the pellets provided by company G. Under the same moisture conditions of 0.4 and $0.6 \mathrm{w} \mathrm{w}^{-1}$, the pellets provided by company $\mathrm{C}$ were characterized by a water potential of approx. -20 and $-4 \mathrm{MPa}$, respectively, while for the pellets provided by company $G$ these values amounted to approx. -50 and $-1 \mathrm{MPa}$, respectively.

The anticipated relation between pellet's water resistance and GA after 14 days, under the water excess conditions, was also confirmed (Fig. 3a).

A strong correlation was expected between the germination ability of both pelleted and mechanically depelleted seeds. However, it was observed that a strong and significant correlation only existed when the measurements were 

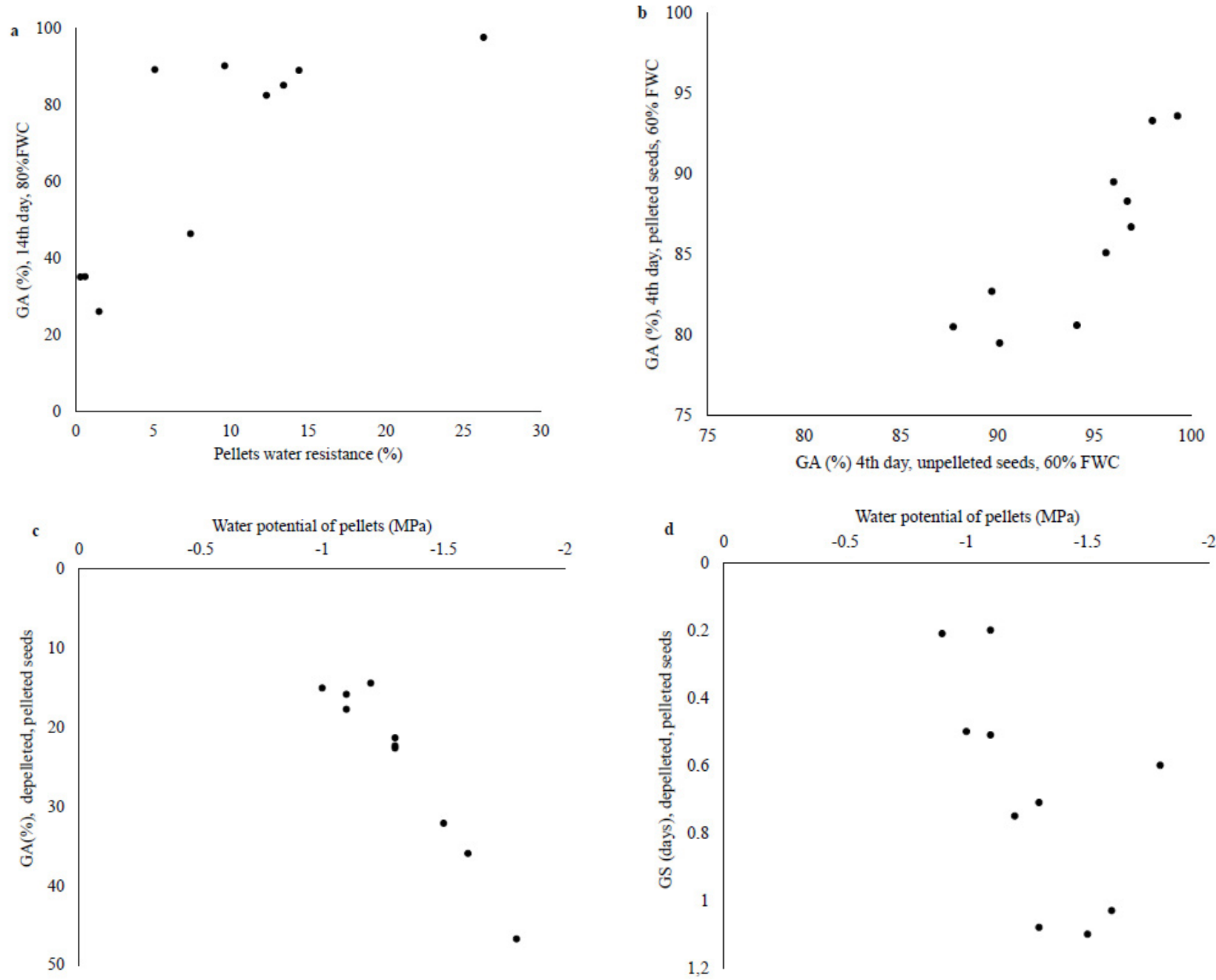

Fig. 3. The relationship between: a - germination ability (GA) 14 days after the commencement of the germination test, at $80 \%$ FWC of filter paper and water resistance of pellets; $b$ - germination ability of pelleted and unpelleted seeds after 4 days, at $60 \%$ (optimum) FWC of filter paper; $\mathrm{c}, \mathrm{d}$ - water potential of pellets and differences between unpelleted and pelleted seeds in the germination ability after 4 days, as well as differences in the germination speed of one seed (40\%) FWC of filter paper, respectively.

conducted after 14 days. For the measurements taken after 4 days, a strong relation between the germination of pelleted and non-pelleted seeds only occurred under the optimum moisture conditions (Fig. 3b). Under a shortfall or excess of water in the filter paper, the connection was weaker and statistically insignificant.

As regards the reaction of seeds provided by different companies to varied environmental conditions, it can be assumed that it was related to pellet's water resistance and water potential.

Under the water shortfall conditions in the germination medium, the low water potential of pellets inhibited seed germination, which was demonstrated by a large difference in the germination ability and germination speed (GS), determined between mechanically depelleted and pelleted seeds (Fig. 3c and 3d).
Pellet properties can affect the respiration rate under the water excess conditions in the filter paper (Table 4). On each day of the germination process, the seeds belonging to company $\mathrm{C}$ were characterized by a greater respiration intensity than the seeds manufactured by company $\mathrm{G}$. Within a 3 days period, the seeds provided by company $\mathrm{G}$ did not germinate at all, while $8 \%$ of the seeds belonging to company $\mathrm{C}$ germinated after 2 days, and $36.2 \%$ after 3 days.

Significant differences between companies in the chemical element content in the pellets were measured.

The greatest variation applied to copper whose content in the pellets provided by company B was 91 times greater than in the pellets belonging to company D. A low variability in the chemical element content in the pellets of different companies occurred for zinc, manganese and lead (Table 5). 

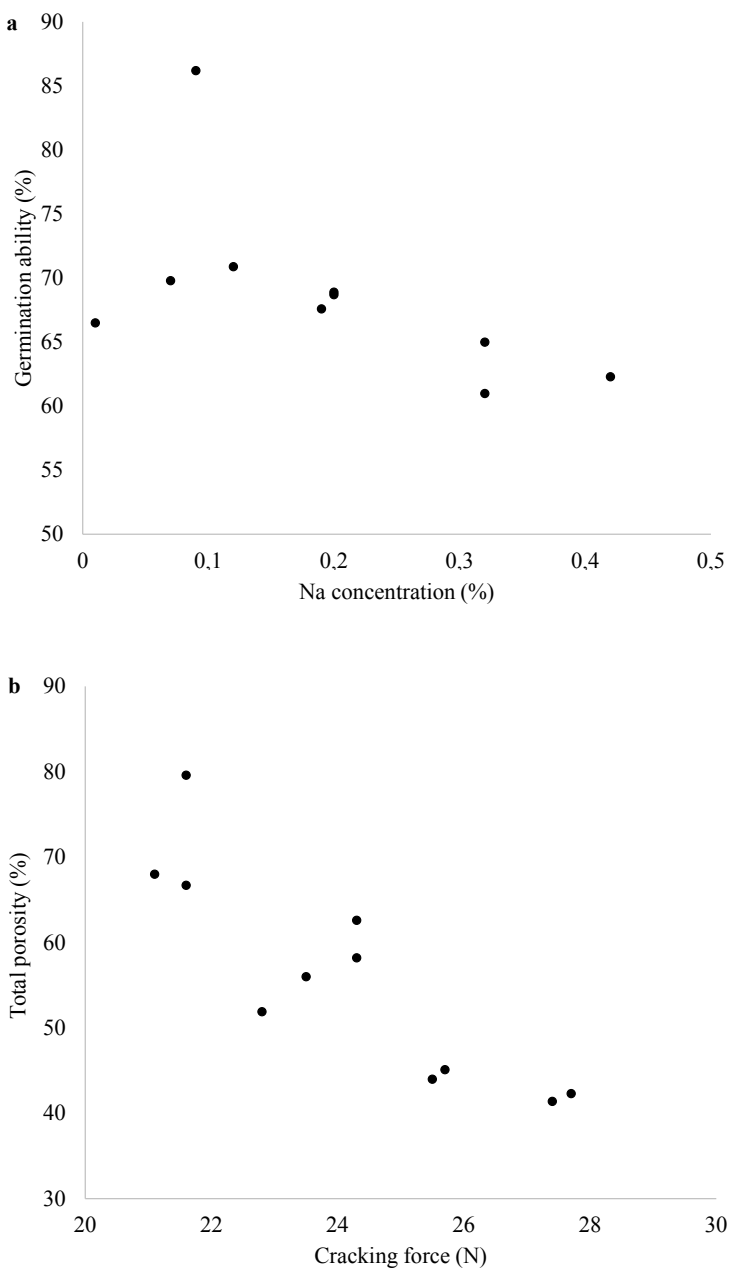

Fig. 4. Relationship between: a - germination ability (day 4), 40\% FWC and Na concentration, $\mathrm{b}$ - total porosity and cracking force of pellets.

Table 4. Respiration ( $\mathrm{mg} \mathrm{CO} \mathrm{CO}_{2} \mathrm{~g}^{-1}$ fresh mass $\mathrm{h}^{-1}$ ) of pelleted seeds, germinating with an excess of water in the germinating media. The seeds were produced by companies $\mathrm{C}$ and $\mathrm{G}$

\begin{tabular}{cccc}
\hline \multirow{2}{*}{$\begin{array}{c}\text { Time since } \\
\text { germination } \\
\text { test start }(\mathrm{h})\end{array}$} & \multicolumn{2}{c}{$\begin{array}{c}\text { Seeds produced by } \\
\text { companies }\end{array}$} & \multirow{2}{*}{$\begin{array}{c}\text { Difference } \\
\text { C-G }\end{array}$} \\
\cline { 2 - 3 } & $\mathrm{C}$ & $\mathrm{G}$ & \\
\hline 24 & $0.3050 \mathrm{~B}$ & $0.2410 \mathrm{~A}$ & 0.0640 \\
48 & $0.3650 \mathrm{~B}$ & $0.2500 \mathrm{~A}$ & 0.1150 \\
72 & $0.3939 \mathrm{~B}$ & $0.2210 \mathrm{~A}$ & 0.1730 \\
Means & $0.3543 \mathrm{~B}$ & $0.2373 \mathrm{~A}$ & \\
\hline
\end{tabular}

Assuming that the mass of 1000 pelleted fruits was $25 \mathrm{~g}$, it could be assumed that the mass of the pellet on 1 fruit was approx. $15 \mathrm{mg}$. Adding the content of all the heavy metals in the pellet, for company B it was $671.4\left(\mu \mathrm{mol} \mathrm{mol}^{-1}\right)$, and for company D 217. $0\left(\mu \mathrm{mol} \mathrm{mol}^{-1}\right)$. Assuming that the seed rate was 1.3 seed unit per hectare, then 1.3 and $0.42 \mathrm{~g}$ of chemical components would be introduced to an area of 1 ha from the pellets provided by companies B and D, respectively. This was not the amount that could be seemed hazardous to the environment.
The macroelements (Na, K, Mg, Ca, Fe) content in the pellets (Table 5) was much more similar than the microelements content. Upon calculating the elements content to the mass of a single pellet, it was noted that the most monovalent cations that formed chemical compounds by quickly dissolving in water were contained in the pellets manufactured by companies B, G and I. The water potential of these pellets was $-1.57 \mathrm{MPa}$, in average terms, when compared to the mean value obtained for the pellets provided by the other 7 companies (-1.21 MPa). An increase in the Na content decreased the GA determined under the water shortfall conditions after 4 days. The regression equation showed that if the $\mathrm{Na}^{+}$content increased by $0,1 \%$, within the 0.7 to $0.42 \%$ range, the germination ability after 4 days, under the water shortage conditions, decreased by $3 \%$. The pelleted seeds containing approx. $0.1 \% \mathrm{Na}$ in a pellet germinated at up to approx. $80 \%$. An increase in Na content to $0.5 \%$ resulted in decreasing the GA to approx. $62 \%$ (Fig. $4 \mathrm{~b}$ ).

\section{DISCUSSION}

The obtained results demonstrate the importance of assessing pellet's cracking force in the shaping of other physical characteristics of pelleted seeds. The mean cracking force was positively correlated with pellet's abrasion resistance and water resistance, and negatively with pellet's porosity. A similar negative correlation between the porosity and mechanical integrity of pellets was obtained by Pedrini et al. (2017). The high variability of cracking force is probably the result of the seeds in the rotating drum being affected by various forces that result in compacting the pellet to a lesser or greater extent.

Pellet's water resistance appears extremely important for its characteristics. Under the water excess conditions in the germination medium, the pellet is likely to lose its structure and start to slake, which then hampers the oxygen access and inhibits germination. The detrimental effect of excessive water in the filter paper on the germination of beet seeds was described by Perry and Harrison (1974), and by Podlaski $(1997,2000)$. The issue is whether, and to what extent, the effect of excessive water occurs in the soil where water availability is lower than on the filter paper.

Water imbibition results in the swelling of pellets and seeds. A high swelling ability of pellets improves the seedsoil contact. Blunk et al. (2017) suggested that the sugar beet seed-soil contact was very low. In our research, differences in pellet's swelling ability were probably caused by the use of materials of different types and quality for pelleting. On the basis of the electron microscope photography, it can be stated that the pellets provided by company $\mathrm{C}$ contained a lot of mineral components (Litwiniak, 2006). Pellets built of mineral parts are characterized by a relatively constant humidity under various moisture conditions of the substrate. The pellets manufactured by company $\mathrm{B}$ were made of organic material with a high absorption 
Table 5. Content of some mineral elements in the pellets. Means for different varieties from the same company

\begin{tabular}{|c|c|c|c|c|c|c|c|c|c|c|c|c|c|}
\hline \multirow{2}{*}{$\begin{array}{l}\text { Com- } \\
\text { panies }\end{array}$} & $\mathrm{Cu}$ & $\mathrm{Zn}$ & $\mathrm{Mn}$ & $\mathrm{Ni}$ & $\mathrm{Cr}$ & $\mathrm{Pb}$ & $\mathrm{Cd}$ & $\mathrm{Cr}$ & $\mathrm{Na}$ & $\mathrm{K}$ & $\mathrm{Mg}$ & $\mathrm{Ca}$ & $\mathrm{Fe}$ \\
\hline & \multicolumn{8}{|c|}{$\mu \mathrm{mol} \mathrm{mol}^{-1}$} & \multicolumn{5}{|c|}{$\%$} \\
\hline A & $28.1 \mathrm{~b}$ & $35.3 \mathrm{~cd}$ & $174.0 \mathrm{~d}$ & $5.7 b$ & $10.2 \mathrm{c}$ & $5.2 \mathrm{a}$ & $0.50 \mathrm{~d}$ & $6.6 \mathrm{a}$ & $0.20 \mathrm{~b}$ & $0.36 \mathrm{~d}$ & $1.19 \mathrm{~g}$ & $0.63 \mathrm{~d}$ & $0.48 \mathrm{a}$ \\
\hline B & $465.0 \mathrm{e}$ & $22.9 a$ & $128.0 \mathrm{c}$ & $2.2 \mathrm{a}$ & $3.4 \mathrm{a}$ & $10.1 \mathrm{c}$ & $0.11 \mathrm{a}$ & $39.7 b$ & $0.32 \mathrm{c}$ & $0.35 \mathrm{~d}$ & $0.49 \mathrm{~b}$ & $0.34 \mathrm{a}$ & $0.52 \mathrm{a}$ \\
\hline $\mathrm{C}$ & $265.2 d$ & $36.1 \mathrm{~d}$ & $187.5 \mathrm{~d}$ & $8.8 \mathrm{~d}$ & $10.2 \mathrm{c}$ & $4.9 \mathrm{a}$ & $0.42 \mathrm{c}$ & $60.5 c$ & $0.07 \mathrm{a}$ & $0.26 b$ & $0.21 \mathrm{a}$ & $1.48 \mathrm{~h}$ & $0.66 \mathrm{~b}$ \\
\hline $\mathrm{D}$ & $5.1 \mathrm{a}$ & $50.3 f$ & $97.5 b$ & $6.8 \mathrm{c}$ & $7.0 \mathrm{~b}$ & $10.5 \mathrm{c}$ & $0.14 b$ & $39.7 b$ & $0.09 \mathrm{a}$ & $0.30 \mathrm{c}$ & $0.57 \mathrm{c}$ & $0.46 b$ & $2.63 \mathrm{f}$ \\
\hline $\mathrm{E}$ & $6.2 \mathrm{a}$ & $50.6 f$ & $90.0 \mathrm{~b}$ & $6.5 \mathrm{bc}$ & $6.2 b$ & $10.1 \mathrm{c}$ & $0.51 \mathrm{~d}$ & $115.0 \mathrm{~d}$ & $0.10 \mathrm{~b}$ & $0.25 b$ & $0.61 \mathrm{~d}$ & $0.53 \mathrm{c}$ & $2.75 \mathrm{~g}$ \\
\hline $\mathrm{F}$ & $24.9 b$ & $27.9 \mathrm{~b}$ & $17.8 \mathrm{a}$ & $5.1 \mathrm{~b}$ & $7.8 \mathrm{~b}$ & $5.4 \mathrm{a}$ & $0.64 \mathrm{e}$ & $224.8 \mathrm{~g}$ & $0.19 \mathrm{~b}$ & $0.34 \mathrm{~d}$ & $1.31 \mathrm{~h}$ & $0.58 \mathrm{~cd}$ & $0.56 \mathrm{ab}$ \\
\hline G & $68.6 \mathrm{c}$ & $42.0 \mathrm{e}$ & $91.2 b$ & $6.2 \mathrm{bc}$ & $5.8 \mathrm{ab}$ & $8.6 \mathrm{~b}$ & $0.54 \mathrm{~d}$ & $252.5 \mathrm{~h}$ & $0.20 \mathrm{~b}$ & $0.42 \mathrm{e}$ & $1.20 \mathrm{~g}$ & $0.70 \mathrm{e}$ & $0.54 \mathrm{a}$ \\
\hline $\mathrm{H}$ & $68.6 \mathrm{c}$ & $42.0 \mathrm{e}$ & $91.2 b$ & $6.2 \mathrm{bc}$ & $5.8 \mathrm{ab}$ & $8.6 b$ & $0.54 \mathrm{~d}$ & $252.5 \mathrm{~h}$ & $0.12 \mathrm{a}$ & $0.16 \mathrm{a}$ & $0.48 b$ & $0.70 \mathrm{e}$ & $2.23 \mathrm{e}$ \\
\hline I & $63.4 \mathrm{c}$ & $32.2 \mathrm{c}$ & $175.2 d$ & $36.4 \mathrm{e}$ & $14.0 \mathrm{~d}$ & $5.7 \mathrm{a}$ & $0.66 \mathrm{e}$ & $206.8 \mathrm{f}$ & $0.42 \mathrm{~d}$ & $0.46 \mathrm{f}$ & $0.80 \mathrm{e}$ & $1.10 \mathrm{~g}$ & $0.99 \mathrm{c}$ \\
\hline $\mathrm{J}$ & $24.3 b$ & 39.0de & $181.8 \mathrm{~d}$ & $35.2 \mathrm{e}$ & $15.0 \mathrm{~d}$ & $8.9 b$ & $0.66 \mathrm{e}$ & $166.3 \mathrm{e}$ & $0.32 \mathrm{c}$ & $0.28 b$ & $0.83 f$ & $0.95 f$ & $1.35 \mathrm{~d}$ \\
\hline Means & 101.9 & 37.8 & 123.4 & 12.0 & 8.54 & 7.8 & 0.47 & 136.4 & 0.20 & 0.32 & 0.77 & 0.75 & 1.27 \\
\hline
\end{tabular}

of water and swelling ability. Based on the analysis conducted by WULS peat specialists, the organic material in pellets was peat. Many seeds swell during imbibition, and the swollen seeds impose certain compacting forces on the particles around them, thus improving their contact with the soil and reducing the seed-soil impedance. At the same time, they reduce the water content in the soil in the immediate vicinity of the seed, which may cause an increase in the mechanical resistance of the radicle (Hadas, 2004). The same explanation of the higher amount of soil around pelleted seeds, in comparison to naked seeds, was presented by Blunk et al. (2017).

It was observed during the study that the pelleted seeds provided by company B swelled three times as much as the seeds obtained from company C. Similarly, the water content in the pellets of these seeds differed by a factor of two. It is probable that the pellets manufactured by company $\mathrm{B}$ were made of organic material comprising cellulose and hemicellulose, with a high water absorption ability. Litwiniak (2006), in comparing various pellets, noted the relation between the pellet and the germinating media moisture content. There were pellets characterized by a relatively constant or varying water content, depending on the moisture conditions of germination.

The study concludes that, under the water shortfall conditions in the germination medium, low pellet water potential was a factor affecting the germination rate. Under the water excess conditions, germination was determined by pellet's water resistance. The pellets manufactured by different companies were characterized by different dynamics of the water potential change during pellet saturation with water. The seeds whose pellets were characterized by a lower water potential displayed slower germination with the same moisture content. In order to germinate, sugar beet seeds must reach a minimum water potential of about
-1.0 MPA (Bradford, 1994; Podlaski, 1997). Every factor that decreases the water potential of either the germination medium or the pellet, extends its germination time.

It is possible that, under the water shortfall or excess conditions in the germination medium, other pellet characteristics, such as water potential or water resistance, reduce the strength of the relation between the germination of pelleted and non-pelleted seeds.

Both under the water shortfall and excess conditions in the germination medium, the pellet characteristics have a greater effect on the drawing of water and on the water flow between the pellet and the seed than under the optimum moisture conditions.

The study has demonstrated a significant variation in the chemical composition of individual pellets during the study years. Similar results were obtained by Litwiniak (2006). Pellets manufactured by certain companies were characterized by relative stability in the chemical composition, while for others a high variability was observed. This may have been caused, for example, by different doses and compositions of the pesticides used. It is probable that a high content of monovalent ions was connected with the lower water potential of pellets and GA under a deficit of water in filter paper.

Summing up, a closer collaboration between the academic circles and the seed industry is needed for fully tapping on the potential offered by seed pelleting for the enhancement of plant establishment and performance. The integration of academic research and seed industry studies could be very beneficial for developing more effective and environmentally-friendly seed treatment methods.

\section{CONCLUSIONS}

1. Pellet's cracking force and water resistance are the basic parameters of pellet quality. 
2. Under the water shortfall and excess of water conditions in germination media, germination was affected by low water potential and pellets water resistance respectively.

3 . The swelling ability of pellets is determined by their organic or monaural composition.

4. Pellets differ in their chemical composition, the highest and the lowest variability among pellets originating from different companies were observed for $\mathrm{Cu}$ and $\mathrm{K}$ ions respectively.

5. Both under the water shortfall and excess conditions in the germination medium, the pellet physicochemical properties have a greater effect on the drawing of water, and on the water flow between the pellet and the seeds than under the optimum moisture conditions.

Conflict of interest: The Authors do not declare conflict of interest.

\section{REFERENCES}

Blunk S., Malik A.H., Heer M.I., Ekblad T., Bussel J., Sparkes D., Fredlund K., Sturrock C.J., and Mooney S.J., 2017. Quantification of seed-soil contact of sugar beet (Beta vulgaris) using X-ray Computed Tomography. Plant Methods 13,71-82, https://doi.org/10.1186/s13007-017-0220-4

Bradford K.J., 1994. Water stress and the water relations of seed development: A critical review. Crop Science, 34, 1-11. https://doi.org/10.2135/cropsci1994.0011183X003400010 $001 \mathrm{x}$

Copeland L.O. and McDonald M.B., 2001. Seed enhancement. In: Principles of seed science and technology. Springer, Boston, MA, https://doi.org/10.1007/978-1-4615-1619-4_13

Hadas A., 2004. Seedbed preparation-The soil physical environment of germinating seeds. In Handbook of seed physiology. Applications to agriculture (Eds R.L. Bench-Arnold and R. A. Sanchez), pp 3-36, The Haworth Press, Inc., Binghamton, NY, USA.

Halmer P., 2000. Commercial seed treatment technology. In: Seed technology and its biological basis (Eds M. Black and J.D. Bewley), 257-286, Sheffield Academic Press Ltd., Sheffield England.
Harris Moran Seed Company, 2012. Putting pellets around seed - A science and an art. Seed Technology Newsletter, 6, www.harrismoran.com.

Hoseini M., Fegenabi F., Fajbaksh M., and Babaradeh-Igdir H., 2013. Introduction of seed treatment techniques (seed priming). Int. J. Biosci., 3, 5, 1-12. doi:org/10.12692/ $\mathrm{ijb} / 3.5 \cdot 1-12$

Litwiniak S., 2006. Properties of seeds and pellets affecting germination of pelleted sugar beet seeds (in Polish). Ph.D Thesis, Warsaw University of Life Sciences, Warsaw, Poland.

Pedrini S., Meritt D.J., Stevens J., and Dixon K., 2017. Seed coating: Science or marketing spin? Trends in Plant Science, 22,2,106-116.https://doi.org/10.1016/j.tplants.2016.11.002

Perry D.A. and Harrison J.G., 1974. Studies on the sensitivity of monogerm sugar beet germination to water. Ann. Appl. Biol., 77, 51-60, https://doi.org/10.1111/j.1744-7348.1974. tb01387.x

Podlaski S., 1997. Physical and chemical properties of pelleted seeds affecting its germination ability (in Polish). Int. Conf. Progress in Sugar Beet Cultivation and Root Quality, September 4-5, Warsaw, Poland.

Podlaski S., 2000. Properties of sugar beet fruits affecting germination, field emergence and growth of plants. Part III. Factors affecting fruits and seed moisture content. Annuals of Agricultural Sciences, series A, 115, 31-39.

Podlaski S., Tul A., Oracz K., Chomontowski Ch., Malek J., and Siejko P., 2016. Method for stimulation of seeds. Patent No. 16738888.3-1110, PL/25.05.15/PLA 41247115. European Patent Office, Munich, Germany.

Sekhon B.S., 2014. Nanotechnology in agri-food production: an overview. Nanotechnol. Sci. Appl., 7, 31-53. doi:102147/ NSA.S39406

Taylor A.G., Allen P.S., Benett M.A., Bradford K.J., Burris J.S., and Misra M.K., 1998. Seed enhancements. Seed Sci. Res., 8,245-256,https://doi.org/10.1017/S0960258500004141

Taylor A.G. and Salanenka Y.A., 2012. Seed treatments: phytotoxicity amelioration and traces uptake. Seed Sci. Res., 22, S1, 586-590. https://doi.org/10.1017/S0960258511000389 